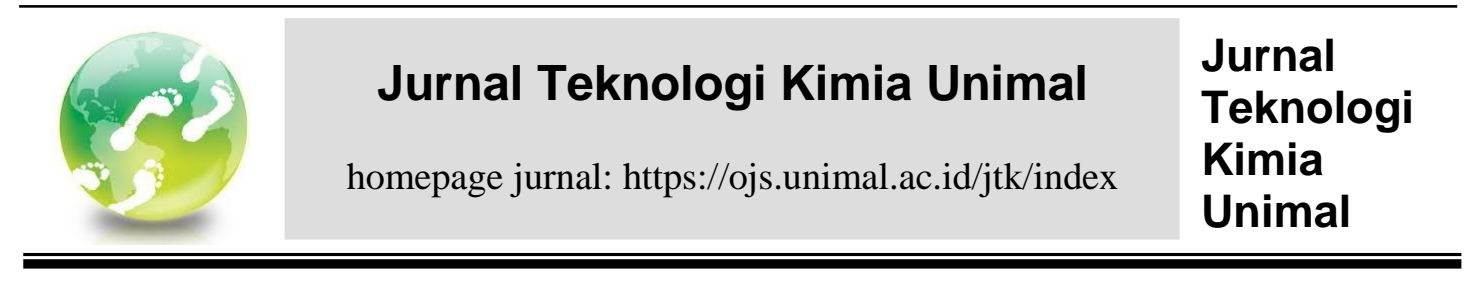

\title{
ANALISA KANDUNGAN PATCHOULI ALCOHOL DALAM FORMULASI SEDIAAN MINYAK NILAM ACEH UTARA (POGOSTEMON CABLIN BENTH) SEBAGAI ZAT PENGIKAT PADA PARFUM (EAU DE TOILETTE)
}

\author{
Zainuddin Ginting ${ }^{1}$, Ishak ${ }^{1}$, Muhammad Ilyas ${ }^{1}$ \\ ${ }^{1}$ Program Studi Teknik Kimia, Fakultas Teknik, Universitas Malikussaleh, \\ Kampus Utama Jl. Cot Tengku Nie, Reuleut, Muara Batu, Aceh Utara, \\ Aceh , Indonesia. E-mail: zginting@ unimal.ac.id
}

\begin{abstract}
Abstrak
Tanaman nilam merupakan salah satu tanaman penghasil minyak atsiri yang cukup penting sebagai komoditi ekspor Indonesia dan menyumbang devisa sekitar 60\% dari total ekspor minyak atsiri nasional. Indonesia merupakan pemasok minyak nilam terbesar dunia dengan kontribusi $90 \%$. Minyak nilam digunakan sebagai zat pengikat (fixative agent) dalam industri parfum yang tidak dapat diganti oleh zat sintetik karena sangat berperan dalam menentukan kekuatan, sifat dan ketahanan aroma. Tujuan penelitian ini adalah membuat formula pewangi jenis eau de toilette dengan bahan pewangi alami menggunakan minyak atsiri tanaman nilam dam tambahan pewangi lainnya. Penelitian ini melakukan uji rendemen minyak nilam, uji densitas minyak nilam, uji Patchouli Alcohol menggunakan GC-MS minyak nilam, uji warna parfum, uji densitas parfum dan uji organoleptik dengan parameter kesukaan terhadap aroma serta ketahanan aroma parfum. Uji rendemen minyak nilam melalui proses penyulingan dengan menggunakan bahan baku tanaman nilam sebanyak $30.000 \mathrm{gr}$ menghasilkan minyak nilam sebanyak 800 gr sehingga rendemen yang didapat sebesar 2,67\%. Uji densitas minyak nilam yang didapat sebesar 0,904 gr. Uji GC-MS menunjukkan komponen senyawa Patchouli Alcohol (PA) pada minyak nilam sebesar 34,23\%. Pengujian warna parfum menunjukkan pengaruh konsentrasi minyak nilam dimana semakin banyak minyak nilam dalam formula maka warna parfum semakin menuju coklat tua dan semakin jernih warna parfum maka kandungan minyak nilam di dalamnya semakin sedikit. Pengujian berat jenis parfum minyak nilam menunjukkan semakin banyak kandungan minyak nilam maka berat jenis parfum akan semakin naik., formula $B_{5} S_{5} T_{2} M_{2}$ menunjukkan parfum dengan berat jenis terbesar yaitu berkisar $4,81 \mathrm{gr} / \mathrm{mL}$ dan berat jenis ratarata berkisar 4,66 $\mathrm{gr} / \mathrm{mL}$. Uji organoleptik pada formula parfum dengan mencampurkan $10 \mathrm{~mL}$ zat pewangi, lalu ditambahkan zat pengikat (minyak nilam) dan zat pelarut (Etanol) sebanyak $5 \mathrm{~mL}$. Berdasarkan uji organoleptik kesukaan aroma terpilih tiga formula dengan nilai tertinggi. Formula terbaik dengan nilai kesukaan aroma tertinggi ialah formula $B_{2} S_{2} T_{2} M_{2}$ (nilam $2 \mathrm{ml}$, etanol $3 \mathrm{ml}$, lemon $4 \mathrm{ml}$, kopi $6 \mathrm{ml}$ ) dengan nilai 38. Hasil pengujian ketahanan aroma parfum menunjukkan Formula yang memiliki daya tahan aroma yang tercepat adalah formula $B_{1} S_{1} T_{1} M_{1}$ dan $B_{1} S_{1} T_{5} M_{5}$ dengan waktu 14 jam sedangkan formula yang
\end{abstract}


memiliki daya tahan aroma yang terlama adalah $B_{5} S_{5} T_{5} M_{5}$ dan $B_{5} S_{5} T_{6} M_{6}$ dengan waktu 51 jam.

Kata kunci: $\quad$ Eau De Toilette, Fixative agent, Formula, Minyak atsiri, Nilam

\section{Pendahuluan}

Indonesia memiliki sumber daya alam hayati maupun hewani yang sangat beragam. Indonesia merupakan penghasil minyak atsiri terbesar yang cukup penting di pasar dunia, yaitu terdapat lebih 80 jenis minyak atsiri yang diperdagangkan. Indonesia sendiri memiliki 40 jenis minyak atsiri yang dapat diperdagangkan, namun hanya sekitar 14 jenis minyak atsiri yang memasuki pasar dunia, diantaranya minyak nilam, minyak pala, minyak kenanga, minyak gaharu, minyak akar wangi, minyak kayu putih, minyak sereh wangi,minyak cengkeh, minyak lada, minyak melati, minyak jahe, minyak kemukus dan minyak cendana (BPS, 2005).

Minyak atsiri dikenal juga dengan nama minyak eteris atau minyak terbang (essential oil, volatil oil) yangdihasilkan oleh tanaman. Diperoleh dari akar, batang, daun maupun bunga tanaman. Minyak atsiri mempunyai sifat-sifat mudah menguap pada suhu kamar tanpa mengalami dekomposisi, mempunyai rasa getir (pungent taste), berbau wangi sesuai dengan bau tanamannya, umumnya larutdalam pelarut organik dan tidak larut dalam air.Minyak atsiri dalam industri digunakan sebagai kosmetik, parfum, antiseptik, obat-obatan, flavoring agent bahan pangan atau minuman dan aromatheraphy (Suhirman, 2009).

Tanaman nilam merupakan salah satu tanaman penghasil minyak atsiri yang cukup penting sebagai komoditi ekspor Indonesia dan menyumbang devisa sekitar $60 \%$ dari total ekspor minyakatsiri nasional. Indonesia merupakan pemasok minyak nilam terbesar dunia dengan kontribusi $90 \%$. Minyak nilam digunakan sebagai zat pengikat (fixative) dalam industri parfum yang tidak dapat diganti oleh zat sintetik karena sangat berperan dalam menentukan kekuatan, sifat dan ketahanan aroma. Di Indonesia, nilam menjadi penghasil utama minyak atsiri yang diekspor ke berbagai negara seperti Perancis, Singapura, Amerika Serikat, Inggris, Jerman, India, Spanyol dan Belanda (Novita, 2012). 
Nilam Aceh merupakan nilam terbaik kedua di dunia yang dapat menghasilkan minyak nilam dengan kandungan Patchouli Alcohol (PA) diatas 30\%. Kabupaten Aceh Utara dan Kota Lhokseumawe merupakan kabupaten kota di Provinsi Aceh yang masih sangat mengandalkan sektor pertanian pangan dan perkebunan. Sektor pertanian memiliki potensi yang sangat besar untuk mendukung perekonomian masyarakat Lhokseumawe-Aceh utara. Dari semua kecamatan yang ada di wilayah Lhokseumawe-Aceh Utara, Kecamatan Cot Girek merupakan kecamatan yang sebagian besar masyarakatnya berprofesi sebagai wiraswasta dan petani, salah satu usaha petani di Kecamatan Cot Girek yaitu membudidayakan tanaman nilam (BAPPEDA Aceh, 2015).

Parfum merupakan produk yang semakin berkembang saat ini, terdapat dua jenis bahan pewangi yang sering digunakan yaitu, pewangi sintetik dan pewangi alami. Pewangi sintetik memiliki wangi yang lebih tajam, sehingga dapat menimbulkan rasa pusing dan kurang nyaman, sedangkan pewangi alami memiliki wangi yang lebih lembut sehingga lebih nyaman digunakan dan pewangi alami juga dapat meminimalisasi resiko keracunan parfum (Hikmah, 2017).

Parfum dengan pewangi alamitidak hanyaaman untuk kesehatan, namun juga memiliki manfaat baik untuk suasana hati dan emosi.Jika kita merasa sedih, aroma juga dapat menciptakan suasana hati lebih baik, dengan semprot atau oleskan parfum, maka kita dapatmenikmati manfaat aromaterapinya. Ini tidak hanya akan menghilangkan stres dan meringankan pikiran, tetapi juga akan meningkatkan tingkat energi dan membuat kita lebih waspada, sehinggakita akan lebih produktif dalam bekerja. Karena ketika kita wangi maka kitakan merasa lebih baik dan menjadi lebih percaya diri (Hikmah, 2017).

Hasil analisis menggunakan GC-MS diperoh hasil bahwa komponen penyusun utama pada minyak atsiri nilam menggunakan air $\mathrm{pH} 7$ yaitu alphaguaiene $(14,12 \%)$, seychellene $(8,16 \%)$, alpha-patchoulene $(5,94 \%)$, deltaguaiene $(15,42 \%)$ dan patchouli alkohol (34,5\%) (Heni Setiyowati, 2013).

Hasil survei pada penelitian terdahulu menguji minyak nilam, akar wangi, dan vanila sebagai base note. Minyak-minyak tersebut berfungsi sebagai fiksatif yang dapat mempertahankan wangi. Metode trial and error dilakukan untuk menentukan base note yang sesuai dengan produk eau de toilette yangdiharapkan. 
Formula diharapkan memiliki wangi yang menyenangkan mengarahpada kesan bunga-bungaan yang segar dan memiliki warna yang baik ditandaidengan campuran larutan yang homogen (Anik, 2014).

Minyak nilam terpilih sebagai base noteterbaik dikarena minyak nilam memiliki keserasianaroma yang paling cocok dibandingkan minyak akar wangi dan vanila saatdipadukan dengan minyak-minyak terpilih pada middle dan top note yakni wangifloral dan citrus. Minyak nilam telah larut sempurna pada bioetanol $96 \%$ denganwarna larutan coklat kekuningan. minyak nilam yang digunakan memiliki kadar patchouli alcohol sekitar 27\%,komponen ini merupakan golongan terpen-o sehingga memudahkan kelarutan minyak nilam dalam alkohol (Anik, 2014).

Adapun syarat mutu minyak nilam sesuai dengan SNI 06-2385-2006 dapat dilihat pada Tabel 2.2 adalah sebagai berikut:

\begin{tabular}{ccc}
\hline Jenis Uji & Satuan & Persyaratan \\
\hline Warna & - & Kuning muda - coklat \\
kobot Jenis $25^{\circ} \mathrm{C}$ & - & $0,950-0,975$ \\
Indeks bias $\left(\mathrm{nD}^{20}\right)$ & - & $1,507-1,515$ \\
Kelarutan dalam etanol $90 \%$ & & Larutan jernih atau opalesensi \\
pada suhu $20^{\circ} \mathrm{C} \pm 30^{\circ} \mathrm{C}$ & ringan dalam perbandingan \\
Bilangan asam & minyak & volume $1: 10$ \\
Bilangan ester & minyak & Maksimal 8 \\
Putaran optik & $\mathrm{O}$ & Maksimal 20 \\
Patchouli alcohol $\left(\mathrm{C}_{15} \mathrm{H}_{26} \mathrm{O}\right)$ & $\%$ & $(-) 48-(-) 65$ \\
Alpha copaene $\left(\mathrm{C}_{15} \mathrm{H}_{24}\right)$ & $\%$ & Minimal 30 \\
Kandungan besi $(\mathrm{Fe})$ & mg/kg & Maksimal 0.5 \\
\hline Sumber : Standar Nasional Indonesia untuk Minyak Nilam (SNI 06-2385-2006)
\end{tabular}

\section{Bahan dan Metode}


Bahan-bahan yang digunakan adalah tanaman nilam, etanol, air, pewangi lemon, pewangi beri, pewangi kopi, dan pewangi melati. Peralatan yang digunakan adalah tungku api, ketel uap, ketel bahan, kondensor, bak penampung produk, labu ukur, pipet volume, bola penghisap, neraca digital, dan piknometer.

Tahapan pelaksanaan penelitian dimulai dari bahan baku nilam Aceh dijemur dan disimpan selama 2 hari dan dipotong kecil-kecil. Selanjutnya dimasukkan kedalam ketel bahan sebanyak 25 kg. Siapkan 300 liter air didalam ketel uap lalu panaskan agar menjadi steam. Steam dialirkan kedalam ketel bahan untuk pemanasan nilam selama 4 jam dan menghasilkan minyak nilam. Kemudian minyak nilam di kondensasi untuk merubah fasa menjadi cair. Amati waktu penyulingan, suhu air pendingin dan kandungan minyak pada air kondensat. Kondensat yang dihasilkan dimasukkan kedalam tabung pemisah untuk memisahkan antara air dan minyak nilam. Hasil penyulingan di analisa kandungannya.

Minyak nilam hasil penyulingan diformulasikan dengan zat pewangi dan pelarut. Kemudian dimasukkan $10 \mathrm{~mL}$ zat pewangi sesuai perbandingan (top note:middle note) yang telah ditentukan ke dalam labu ukur $150 \mathrm{~mL}$. Lalu ditambahkan zat pengikat (minyak nilam) dan zat pelarut (Etanol) sebanyak $5 \mathrm{~mL}$, sesuai perbandingan yang telah ditentukan. Campuran zat pewangi, pengikat dan pelarut, dihomogenasi dengan cara manual selama 1 sampai 2 menit dan diamkan selama 10-15 menit agar tercampur sempurna sehingga aroma parfum bertahan lebih lama. Hasil homogensai parfum yang sudah ditambahkan minyak nilam sebagai fixative di analisa organoleptik.

\section{Hasil dan Diskusi}

\subsection{Uji Rendemen Minyak Nilam}

Uji rendemen merupakan persentase perbandingan antara bahan baku yang digunakan dengan hasil penyulingan (minyak nilam) yang didapat. Semakin banyak minyak nilam yang diperoleh maka nilai rendemen juga ikut tinggi. Persamaan perhitungan rendemen minyak nilam adalah sebagai berikut: 


$$
\begin{aligned}
& \text { Rendemen }(\%)=\frac{\text { Berat Minyak }(\mathrm{gram})}{\text { Berat Sampel }(\mathrm{gram})} \times 100 \% \\
& =\frac{800 \mathrm{gr}}{30000} \times 100 \% \\
& =2,67 \%
\end{aligned}
$$

Minyak nilam diperoleh dengan cara penyulingan uap (Steam Distillation). Setelah penyulingan selama 4 jam, minyak nilam yang dihasilkan berwarna coklat tua/keemasan dengan aroma khas nilamsebanyak $800 \mathrm{~mL}$ dengan berat sampel awal sebanyak $30 \mathrm{~kg}$.Rendemen yang dihasilkan sebesar 2,67\%.

\subsection{Berat Jenis Parfum Minyak Nilam}

Berat jenis minyak nilam didefinisikan sebagai perbandingan antara massa minyak dengan massa air pada volume dan suhu (temperatur) yang sama.

Persamaan perhitungan berat jenis minyak nilam adalah sebagai berikut:

$$
\begin{aligned}
\text { Berat Jenis } & =\frac{\mathrm{W}-\mathrm{W} 0}{\mathrm{~W}-\mathrm{W} 0} \\
& =\frac{17,23-12,68}{17,71-12,68} \\
& =0,904 \mathrm{gr}
\end{aligned}
$$

Hasil persamaan berat jenis menunjukkan bahwa berat jenis minyak nilam berkisar 0,904 gr. Besarkan hasil yang didapat berat jenis minyak nilam sesuai dengan SNI 06-2385-2006 yaitu 0,9 gr. Bobot jenis sering dihubungkan dengan fraksi massa komponen yang terkandung di dalam minyak nilam. Semakin tinggi fraksi massa yang terkandung dalam minyak nilam seperti seskuiterpen, patchouli alcohol, patchoulena, eugenol benzoat, maka semakin besar pula nilai bobot jenis minyak nilam. Hal ini dikarenakan fraksi-fraksi massa tersebut banyak mengandung molekul yang berantai panjang dan relatif banyak ikatan tak jenuh atau banyak gugusan oksigen karena terjadinya reaksi oksidasi (Ahmad, 2014).

\subsection{Uji GC-MS Minyak Nilam}




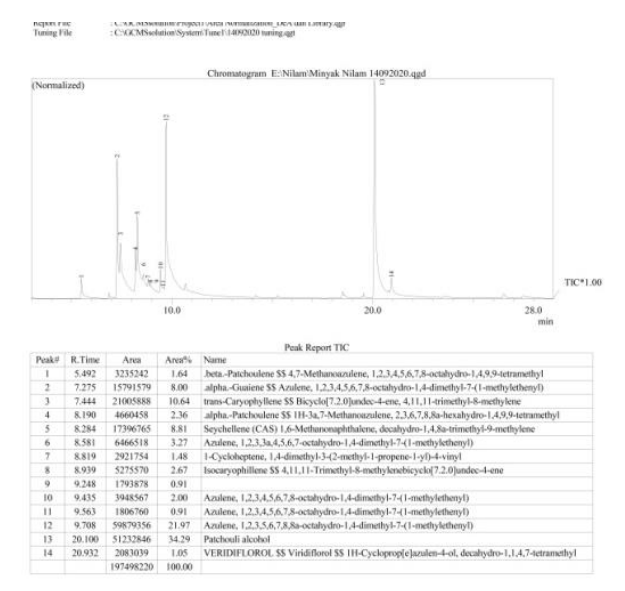

Gambar 3.1 Kromatogram Minyak Nilam

Berdasarkan pada gambar 3.1 kromatogram menunjukkan adanya 13 senyawa dalam minyak nilam dan 3 diantaranya merupakan senyawa yang dominan. Keempat komponen senyawa yang paling dominan secara berturutberturut dimulai dari patchouli alcohol dan methylethenyl dengan masing-masing area sebesar $21,97 \%$ dan 34,29\%. Kandungan patchouli alcohol yang cukup tinggi menjadikan minyak nilam dapat digunakan sebagai base note dalam pembuatan parfum eau de toilette. Minyak nilam mulai menjadi komoditi yang banyak dicari karena mengandung Patchouli alcohol, suatu jenis minyak atsiri yang fungsinya dalam industri sabun, kosmetika, dan parfum yang memiliki daya fiksasi atau daya ikat yang tinggi terhadap bahan pewangi sehingga dapat mengikat aroma wangi serta mencegah penguapan zat pewangi agar tahan lama. (Krismawati, 2005).

\subsection{Uji Warna/Kejernihan Parfum}

Hasil uji visual warna menunjukkan bahwa kejernihan produk sudah cukup baik, kejernihan ini dilihat dari tingkat kehomogenan antara pelarut dan pewangi yang digunakan. Pelarut yang digunakan ialah Ethanol Food Grade 90\%. Uji warna ini melihat kejernihan warna parfum mulai dari coklat tua, coklat, kuning dan kuning muda. Variasi warna menunjukan bahwa semakin banyak minyak nilam dalam suatu formula, maka warna parfum tersebut akan semakin menuju coklat tua dan semakin jernih warna parfum maka kandungan minyak nilam di dalamnya semakin sedikit (Anik, 2014).

\subsection{Uji Organoleptik Parfum Minyak Nilam}


Organoleptik merupakan pengujian berdasarkan pada proses survei lapangan menggunakan panelis secara acak.

\subsection{Uji Kesukaan Aroma}

Aroma merupakan kesan wangi yang lebih lembut memberikan efek aromaterapi. Uji ini dilakukan oleh 10 panelis yang akan memberikan penilaian mulai dari nilai 1 (sangat tidak suka), 2 (tidak suka), 3 (biasa saja), 4 (suka) dan 5 (sangat suka). Berikut hasil uji organoleptik panelis terhadap aroma parfum dapat dilihat pada Gambar 3.3.

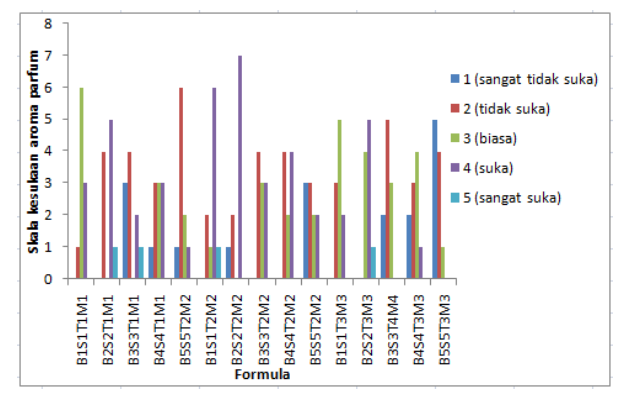

Gambar 3.2 Hasil uji

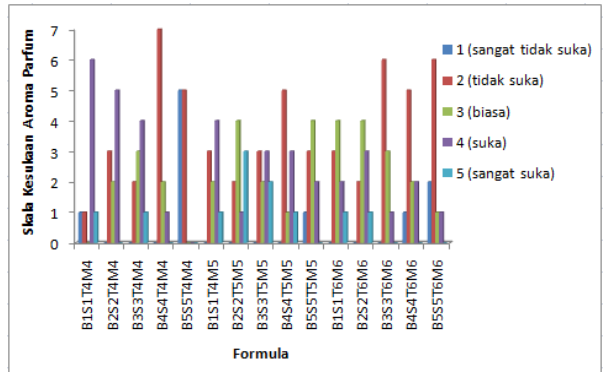

kesukaan aroma parfum minyak nilam

organoleptik

Hasil pengujian organoleptik terhadap kesukaan aroma menyatakan kesukaan tertinggi panelis terhadap parameter kesukaan aroma ialah pada formula $\mathrm{B}_{2} \mathrm{~S}_{2} \mathrm{~T}_{2} \mathrm{M}_{2}, \mathrm{~B}_{2} \mathrm{~S}_{2} \mathrm{~T}_{3} \mathrm{M}_{3}$ dan $\mathrm{B}_{2} \mathrm{~S}_{2} \mathrm{~T}_{4} \mathrm{M}_{4}$. Nilai tertinggi sebesar 38 terdapat pada formula $\mathrm{B}_{2} \mathrm{~S}_{2} \mathrm{~T}_{2} \mathrm{M}_{2}$, nilai 37 yang menyukai aroma formula $\mathrm{B}_{1} \mathrm{~S}_{1} \mathrm{~T}_{4} \mathrm{M}_{4}$ dan nilai 35 menyukai formula $\mathrm{B}_{2} \mathrm{~S}_{2} \mathrm{~T}_{3} \mathrm{M}_{3}$. Formula yang mendapatkan niali kesukaan panelis terendah ialah formula $\mathrm{B}_{5} \mathrm{~S}_{5} \mathrm{~T}_{3} \mathrm{M}_{3}, \mathrm{~B}_{5} \mathrm{~S}_{5} \mathrm{~T}_{4} \mathrm{M}_{4}$ dan $\mathrm{B}_{5} \mathrm{~S}_{5} \mathrm{~T}_{6} \mathrm{M}_{6}$. Formula $\mathrm{B}_{5} \mathrm{~S}_{5} \mathrm{~T}_{4} \mathrm{M}_{4}$ mendapat nilai kesukaan panelis sebesar 15 , Formula $\mathrm{B}_{5} \mathrm{~S}_{5} \mathrm{~T}_{3} \mathrm{M}_{3}$ mendapat nilai kesukaan panelis sebesar 16 dan Formula $\mathrm{B}_{5} \mathrm{~S}_{5} \mathrm{~T}_{3} \mathrm{M}_{3}$ mendapat nilai kesukaan panelis sebesar 21 .

Formula yang mendapat nilai kesukaan aroma tertinggi ialah formula $\mathrm{B}_{2} \mathrm{~S}_{2} \mathrm{~T}_{2} \mathrm{M}_{2}$ (nilam $2 \mathrm{ml}$, etanol $3 \mathrm{ml}$, lemon $4 \mathrm{ml}$, kopi $6 \mathrm{ml}$ ), formula $\mathrm{B}_{2} \mathrm{~S}_{2} \mathrm{~T}_{4} \mathrm{M}_{4}$ 
(nilam $2 \mathrm{ml}$, etanol $3 \mathrm{ml}$, beri $3 \mathrm{ml}$, melati $7 \mathrm{ml}$ ), dan formula $\mathrm{B}_{2} \mathrm{~S}_{2} \mathrm{~T}_{3} \mathrm{M}_{3}$ (nilam 2 $\mathrm{ml}$, etanol $3 \mathrm{ml}$, lemon $5 \mathrm{ml}$, kopi $5 \mathrm{ml}$ ). Pengolahan data organoleptik menunjukkan bahwa formula memberikan hasil yang dapat dipertimbangkan dalam penggunaan aroma parfum eau de toilette. $\mathrm{B}_{2} \mathrm{~S}_{2} \mathrm{~T}_{2} \mathrm{M}_{2}$ (nilam $2 \mathrm{ml}$, etanol 3 $\mathrm{ml}$, lemon $4 \mathrm{ml}$, kopi $6 \mathrm{ml}$ ) dan $\mathrm{B}_{2} \mathrm{~S}_{2} \mathrm{~T}_{3} \mathrm{M}_{3}$ (nilam $2 \mathrm{ml}$, etanol $3 \mathrm{ml}$, lemon $5 \mathrm{ml}$, kopi $5 \mathrm{ml}$ ), berbeda aroma dengan formula $\mathrm{B}_{2} \mathrm{~S}_{2} \mathrm{~T}_{4} \mathrm{M}_{4}$ (nilam $2 \mathrm{ml}$, etanol $3 \mathrm{ml}$, beri $3 \mathrm{ml}$, melati $7 \mathrm{ml}$ ). Formula terpilih dengan nilai tertinggi memiliki komposisi bahan pewangi yang berbeda yaitu dalam formula $\mathrm{B}_{2} \mathrm{~S}_{2} \mathrm{~T}_{2} \mathrm{M}_{2}$ dan $\mathrm{B}_{2} \mathrm{~S}_{2} \mathrm{~T}_{3} \mathrm{M}_{3}$ memiliki karakter aroma yang berbeda dengan komposisi pewangi yang ada di formula $B_{2} S_{2} T_{4} M_{4}$. Formula $B_{2} S_{2} T_{2} M_{2}$ dan $B_{2} S_{2} T_{3} M_{3}$ mengandung minyak kopi sebagai middle note dan minyak lemon sebagai top note, minyak kopi memiliki komponen kimia di dalam kopi seperti kafein, asam klorogenat, trigonelin, karbohidrat, lemak, asam amino, asam organik, mineral dan aroma volatil yang dapat menghasilkan efek aroma terapi, minyak lemon memiliki karakter wangi yang fresh, light, fruity. Formula $\mathrm{B}_{2} \mathrm{~S}_{2} \mathrm{~T}_{4} \mathrm{M}_{4}$ mengandung minyak melati sebagai middle note dan minyak beri sebagai top note, minyak melati memiliki wangi yang floral sweet, minyak beri aroma yang fresh, fruity dan sweet (Farhati \& Muchtaridi 2014).

\subsection{Uji Ketahanan Aroma}

Uji ketahanan wangi dilakukan untuk mengetahui seberapa lama aroma parfum eau de toilette dapat digunakan dan aroma masih dirasakan oleh pengguna. Uji ini dilakukan pada kain katun yang telah disemprotkan parfum dengan melakukan uji secara berskala dengan memberikan penilaian mulai dari nilai 1 (0 jam), 2 (6 jam), 3 (12 jam), 4 (24 jam), 5 (36 jam) dan 6 (48 jam). Berikut adalah grafik hasil uji organoleptik panelis terhadap ketahanan aroma parfum dapat dilihat pada gambar 3.3.

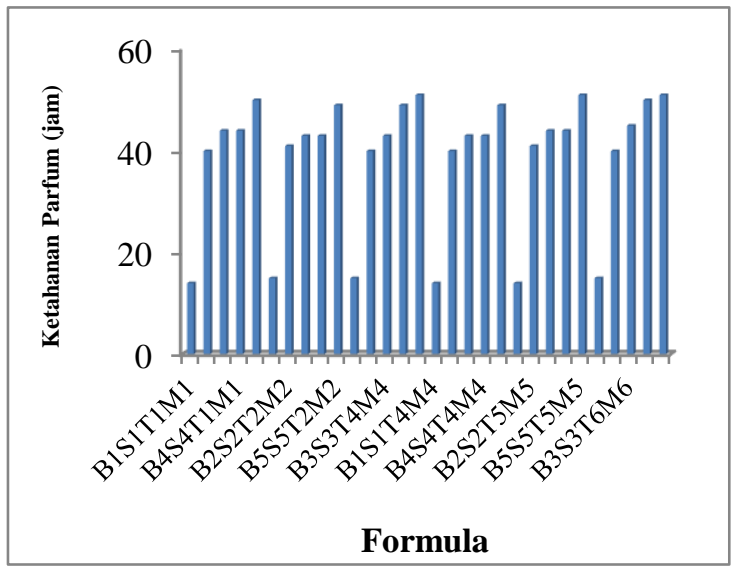


Gambar 3.3 Hasil uji organoleptik ketahanan aroma parfum minyak nilam

Hasil uji organoleptik terhadap ketahanan aroma menyatakan daya tahan parfum terhadap parameter lama waktu yang digunakan ialah pada formula $\mathrm{B}_{5} \mathrm{~S}_{5} \mathrm{~T}_{3} \mathrm{M}_{3}, \mathrm{~B}_{5} \mathrm{~S}_{5} \mathrm{~T}_{5} \mathrm{M}_{5}$ dan $\mathrm{B}_{5} \mathrm{~S}_{5} \mathrm{~T}_{6} \mathrm{M}_{6}$. Ketiga formula memiliki daya ketahanan aroma yang hampir sama yaitu lebih kurang selama 51 jam atau berkisar 2 hari lebih. Formula yang memiliki daya tahan aroma yang rendah adalah formula $\mathrm{B}_{1} \mathrm{~S}_{1} \mathrm{~T}_{1} \mathrm{M}_{1}, \mathrm{~B}_{1} \mathrm{~S}_{1} \mathrm{~T}_{4} \mathrm{M}_{4}$ dan $\mathrm{B}_{1} \mathrm{~S}_{1} \mathrm{~T}_{5} \mathrm{M}_{5}$. Ketiga formula memiliki daya ketahanan aroma yang paling cepat habis yaitu lebih kurang selama 14 jam dengan perlakuan yang sama dalam kondisi dan temperatur ruangan.

Formula yang memiliki daya ketahanan aroma yang tinggi ialah formula $\mathrm{B}_{5} \mathrm{~S}_{5} \mathrm{~T}_{3} \mathrm{M}_{3}$ (nilam $5 \mathrm{ml}$, etanol $0 \mathrm{ml}$, lemon $5 \mathrm{ml}$, kopi $5 \mathrm{ml}$ ), formula $\mathrm{B}_{5} \mathrm{~S}_{5} \mathrm{~T}_{5} \mathrm{M}_{5}$ (nilam $5 \mathrm{ml}$, etanol $0 \mathrm{ml}$, beri $4 \mathrm{ml}$, melati $6 \mathrm{ml}$ ), dan formula $\mathrm{B}_{5} \mathrm{~S}_{5} \mathrm{~T}_{6} \mathrm{M}_{6}$ (nilam 5 $\mathrm{ml}$, etanol $0 \mathrm{ml}$, beri $5 \mathrm{ml}$, melati $5 \mathrm{ml}$ ). Pengolahan data organoleptik menunjukkan bahwa ketiga formula memiliki kesamaan dalam komposisi bahan base note yaitu dengan minyak nilam sebanyak $5 \mathrm{ml}$ tanpa menggunakan pelarut etanol. Ketiga formula memiliki komposisi nilam yang sangat tinggi sehingga mempengaruhi daya tahan parfum eau de toilette dikarenakan minyak nilam memiliki kemampuan fiksasi atau daya ikat aroma yang baik dan memiliki titik didih yang cukup tinggi yaitu sebesar $280,7^{\circ} \mathrm{C}$.

Formula yang memiliki daya tahan aroma yang rendah adalah formula $\mathrm{B}_{1} \mathrm{~S}_{1} \mathrm{~T}_{1} \mathrm{M}_{1}, \mathrm{~B}_{1} \mathrm{~S}_{1} \mathrm{~T}_{4} \mathrm{M}_{4}$ dan $\mathrm{B}_{1} \mathrm{~S}_{1} \mathrm{~T}_{5} \mathrm{M}_{5}$. Ketiga formula memiliki komposisi base note yang sangat rendah bahkan hanya menggunakan etanol, dimana titik didih etanol sebesar $78,1{ }^{\circ} \mathrm{C}$ sehingga memilki tingkat penguapan yang lebih cepat dibandingkan minyak nilam.

\section{Simpulan dan Saran}

Adapun kesimpulan dalam penelitian ini adalah sebagai berikut:

1. Hasil analisa penyulingan minyak nilam yang dihasilkan dengan menggunakan metode penyulingan uap (Steam Distilation) adalah rendemen 
yang dihasilkan sebesar 3,2\% dan berat jenis yang dihasilkan sebesar 0,904 gr.

2. Hasil dari pengujian GC-MS kandungan senyawa pathcouli alcohol yang terkandung dalam minyak nilam hasil penyulingan adalah sebesar 34,29\%.

3. Semakin tinggi konsentrasi minyak nilam maka daya ketahanan aroma parfum akan semakin lama dan sebaliknya.

4. Formula yang terpilih dalam penelitian ini sesuai dengan kesukaan aroma dan ketahanan parfum yaitu B2S2T2M2 (nilam $2 \mathrm{ml}$, etanol $3 \mathrm{ml}$, lemon $4 \mathrm{ml}$, kopi $6 \mathrm{ml}$ ) dengan nilai kesukaan parfum sebesar 38 dan ketahanan parfum selama 41 jam.

Adapun saran yang peneliti berikan adalah tentang peningkatan kandungan senyawa pathcouli alcohol (PA) pada hasil penyulingan minyak nilam dengan menggunakan alat tambahan berupa distilasi/evaporator untuk membantu mengurangi kadar air dan meningkatkan persen PA pada minyak nilam, sehingga dalam formulasi pembuatan parfum minyak nilam, parfum yang dihasilkan akan memberikan kualitas parfum yang lebih baik.

\section{Daftar Pustaka}

1. Ahmad. (2014). Analisis Kualitas Minyak Nilam (Pogostemon Cablin Benth) Produksi Kabupaten Buol. Universitas Tadulako. Palu.

2. Anggraeni, D. (2013). Kinerja Proses Penyulingan Minyak Nilam pada Tekanan Uap dan kepadatan bahan yang berbeda. Skripsi pateta IPB Bogor.

3. Anshory, Jamaludin, A., \& Ace, T. H. (2017). Konsep Dasar Penyulingan dan Analisa Sederhana Minyak Nilam. LPPM- Universitas Padjajaran. W.K. Chen, Linear Networks and Systems (Book style).

4. BAPPEDA. (2015). Sistem Inovasi Industri Nilam Aceh. Aceh: Badan Perencanaan Pembangunan Daerah.

5. Biro Pusat Statistik. (2015). Statistik Perdagangan Luar Negeri, BPS Jakarta.

6. Faizal. (2017). Karakteristik Simplisia dan Isolasi serta Analisis Komponen Minyak Atsiri dari Daun Nilam (Pogostemon Cabin Benth) Asal Aceh Tenggara. Universitas Sumatera Utara: Medan 
7. Farhaty, N. \& Muchtaridi. (2014). Tinjauan kimia dan aspek farmakologi senyawa asam klorogenat pada biji kopi.

8. Fatriani, N. H. (2017). Rendemen dan Kualitas Minyak Atsiri Jahe (Zingiber Officinale Rose). Jurnal Hutan Tropis Borneo. Kalimantan.

9. Isfaroiny, R. d. (2018). Peningkatan Kadar Patchouli Alcohol Pada Minyak Nilam (Pogostemon cablin Benth) Dengan Metode Distilasi Vakum. Skripsi Fakultas MIPA UNESA. Surabaya .

10. Krismawati A. 2005. Nilam dan Potensi Pengembangannya Kalteng Jadikan Komoditas Rintisan. Balai Pengkajian Teknologi Pertanian Kalimantan Tengah. Sinar Tani. Kalimantan.

11. Manurung, T. (2018). Ketua Umum Asosiasi Eksportir Minyak Atsiri Indonesia. (The Indonesian Essential Oil Trade Association/Indessota).

12. Nainggolan. (2015). Pemisahan Komponen Minyak Nilam (Pogostemon Cablin Benth) dengan Teknik Distilasi Fraksinasi Vakum Penelitian. Institut Pertanian Bogor. Bogor.

13. Nuryani, Y. (2017). Budidaya Tanaman Nilam. Balai Penelitian Tanaman Rempah dan Aromatik.

14. Sastroamidjojo, B. 2014. Kimia Minyak Atsiri. Fakultas Pasca Sarjana. Universitas Gajah Mada. Yogyakarta.

15. SNI. (2018). Spesifikasi Persyaratan Mutu Minyak Nilam. Jakarta.

16. Yuhono, J. S. (2017). Strategi Peningkatan Rendemen dan Mutu Minyak dalam Agribisnis Nilam. Balittro Bogor. Bogor. 